\title{
Short-term impact of a university based smoke free campaign
}

\author{
Jean-François Etter, Anne Ronchi, Thomas V Perneger
}

\begin{abstract}
Study objective-The aim of this study was to evaluate the impact of a smoke free programme implemented at the University of Geneva, Switzerland, in 1996. This programme included a prohibition to smoke in university buildings everywhere except in limited areas, and a smoking cessation counselling service.

Methods-Surveys were conducted before and four months after the programme was implemented, in representative samples of programme participants $(n=833)$ and university members not exposed to the programme $(n=1023)$.

Results-In retrospective assessments, participants reported being less bothered by environmental tobacco smoke after programme implementation, but no between group difference was detected in prospective assessments. Relationships between smokers and non-smokers improved moderately in the intervention group and remained unchanged in the comparison group (between group $\mathrm{p}=\mathbf{0 . 0 0 1}$ ). Proportions of smokers who attempted to quit smoking in the past four months increased from $2.0 \%$ to $3.8 \%$ in the intervention group and remained unchanged at $3.5 \%$ in the comparison group (between group difference: $p=0.048$ ). No impact on smoking prevalence $(25 \%)$ was detected. The programme was appreciated by university members, although some of its modalities were criticised.

Conclusion-A regulation prohibiting smoking everywhere but in limited areas of university buildings was acceptable and reduced the perception of bother by environmental tobacco smoke. It did not, however, influence smoking habits or attitudes toward smoking.

(F Epidemiol Community Health 1999;53:710-715)
\end{abstract}

Switzerland is the country that has the sixth highest consumption of cigarettes per adult. ${ }^{1}$ In the past decade, smoking prevalence varied little in Swiss adults but almost doubled among teenagers. ${ }^{2}$ Smoking prevalence is particularly high in Geneva, where $40 \%$ of men and $33 \%$ of women are regular smokers. ${ }^{3}$ In response to that situation, several preventive actions have been implemented in Switzerland in recent years, including school and workplace programmes. These activities were facilitated by a 1993 Federal law aimed at protecting workers from exposure to environmental tobacco smoke.

School and workplace smoking prevention programmes can reach large numbers of participants on repeated occasions, and reviews showed that these programmes can be effective. ${ }^{45}$ In particular, total smoking bans can reduce smoking prevalence and cigarette consumption. ${ }^{6-8}$ However, total smoking bans may not be acceptable in Switzerland, where most smokers are in the "precontemplation" stage of change - that is, have no intention to modify their behaviour. ${ }^{9}$ A regulation that prohibits smoking everywhere but in a limited number of smoking areas could be more acceptable in this population, but the impact of such regulations in European populations is not well documented. In addition, despite the increasing number of school or workplace smoking prevention programmes implemented in Switzerland, none of these programmes has yet been evaluated by means of an experimental or quasi-experimental study design.

This study used a quasi-experimental design to evaluate the impact of a smoke free campaign implemented in the University of Geneva in 1996. The main feature of this campaign was a limited smoking ban.

\section{Methods}

STUDY SETTING

The University of Geneva, Switzerland, includes 12500 students and 4500 academic, administrative or technical collaborators. Until 1996, the university had no global smoking policy. Smoking was permitted everywhere, except in classrooms and auditoriums, as well as in a limited number of no-smoking areas.

THE PROGRAMME

A non-profit local organisation specialised in smoking prevention was commissioned by university authorities to conceive and implement a smoking prevention programme at the university. The programme had three objectives: to decrease exposure to environmental tobacco smoke (ETS) in university buildings, to help smokers quit smoking, and to develop intervention methods suitable for other local schools or workplaces. This organisation appointed a steering committee, which included administrative staff of the university, intermediate level academic staff, students, and an independent expert in communication who had experience in smoking prevention. The programme had three components: (1) a new regulation asking smokers to smoke nowhere but in limited designated areas, (2) a smoking cessation counselling service, and (3) an information campaign. The steering committee chose slogans and communication materials and decided about the location of smoking areas. The smoking cessation counselling 
service was located in the university health service and provided booklets, advice and addresses of smoking cessation clinics outside the university.

After an information campaign in February 1996, the new regulation started in March in four buildings of the university, which included the Faculties of Sciences, Law, Economics and Social sciences. No intervention was implemented in buildings of the Faculties of Psychology and Humanities, which were considered comparison buildings. Assignment of buildings to the intervention or comparison groups was decided by the organisation in charge of the programme and by the evaluators, on the basis of practical and logistic considerations. In intervention buildings, the "nosmoking" surfaces increased from $41 \%$ in September 1995 to $96 \%$ in July 1996, after implementation of the programme. Information on the programme was displayed on 1000 posters, 10000 folded leaflets and various items labelled with the slogan "For a no-smoking University": 12000 mechanical pencils, 3500 lighters and 1000 bookmarks. Lighters were intended to generate comments about and awareness of the programme. In addition, hundreds of smoking cessation self help manuals were distributed in intervention buildings.

STUDY DESIGN AND PARTICIPANTS

The programme was evaluated by the Institute of Social and Preventive Medicine of the University of Geneva, in a controlled beforeafter study. The impact of the programme was assessed with questionnaire data and with various direct observation data. Eligible participants in the questionnaire survey were Geneva residents, university staff, employees or regular students who worked or studied in intervention or comparison buildings. Baseline questionnaires were collected by mail in November and December 1995 and follow up questionnaires seven months later, in June and July 1996. A simple random sample of 3000 university members was drawn from the university administrative file, which included 9702 names from the departments mentioned above. After excluding 92 persons who had left university or moved out of Geneva $(n=86)$ or who were registered twice $(n=6), 2908$ persons were eligible for the first survey and $77 \%$ (2237 of 2908) returned the questionnaire. All participants in the baseline survey were invited to participate in the follow up survey. After exclusion of 53 persons who had left university or moved out of Geneva, participation in the follow up survey was $85 \%$ (1856 of 2184). Up to four reminder mailings were sent to non-respondents on each occasion. ${ }^{10}$ The impact of the programme was assessed in the 1856 persons who returned both the baseline and the follow up questionnaire.

Assignment to the intervention or comparison group was determined from questionnaire data. Persons who had visited the intervention buildings at least once a week between February and June 1996 were included in the intervention group $(n=833)$. Persons who had visited these buildings less than once a week were included in the comparison group $(n=1023)$. Members of the intervention group visited intervention buildings on average 3.3 times a week in this period, and members of the comparison group 0.1 time a week $(\mathrm{p}<0.001)$. Participants were informed that evaluators were independent from university authorities and that confidentiality of the data was guaranteed. The study was approved by the Geneva public health review board.

\section{DATA}

Outcome variables were: exposure to and being bothered by ETS in intervention and comparison university buildings; quality of relationships between smokers and non-smokers in the university; and smoking status, assessed by the question: "Are you currently a cigarette smoker?" Among smokers, we assessed the number of cigarettes per day, the number of minutes between waking up and smoking the first cigarette of the day, the number of quit attempts in the past four months and nicotine dependence (Fagerström test). ${ }^{11}$ As we expected that the programme would have little impact on smoking behaviour, we used three psychometric scales as outcome measures: the stages of change of smoking ${ }^{12}$ and, among smokers only, the "pros and cons" of smoking ${ }^{13}$ and smoking self efficacy. ${ }^{14}$ Because these three constructs predict smoking cessation, ${ }^{12} 1315$ scales measuring these constructs have been proposed as outcome measures for smoking prevention studies. ${ }^{16}$ Finally, participants in the intervention group were questioned about their opinions on and satisfaction with the campaign.

Being bothered by ETS was assessed both prospectively (changes between baseline and follow up in answers to the question "In the (intervention or comparison) university buildings, are you bothered by other people's tobacco smoke?") and retrospectively, in the follow up questionnaire, by the question "Compared to December 1995, are you presently more or less annoyed by tobacco smoke in university (intervention or comparison) buildings?" Questions on bother by ETS were answered by five response options ranging from "Not at all" (coded 0) to "Very much" (coded 100). Exposure to ETS was assessed with Likert-type items with five response options ranging from "Never" (coded 0) to "Very often" (coded 100).

A formal translation protocol was used to adapt published English language questionnaires into French. Four initial translations of the Fagerström test, stages of change and "pros and cons"questionnaires were done by a professional translator, by a translator at the World Health Organisation (WHO) headquarters in Geneva and by two authors (JFE and TVP). A synthesis of these four translations was then prepared by the first author and the head of the French language Translation Department at WHO. This version was then iteratively pre-tested in 54 university members.

We also assessed the impact of the programme on the number of cigarette packs sold in two vending machines, one in the main 
Table 1 Baseline characteristics of participants

\begin{tabular}{lccc}
\hline & $\begin{array}{c}\text { Intervention } \\
\text { group }\end{array}$ & $\begin{array}{l}\text { Comparison } \\
\text { group }\end{array}$ & p value \\
\hline Participants (n) & 833 & 1023 & - \\
Age (mean) & 27.6 & 29.4 & $<0.001$ \\
Men (\%) & 47.9 & 32.6 & $<0.001$ \\
School years (mean) & 16.8 & 17.8 & $<0.001$ \\
Status & & & 0.001 \\
$\quad$ University students (\%) & 79.1 & 84.7 & \\
Academic staff (\%) & 13.3 & 11.6 & \\
Administrative and technical staff (\%) & 7.6 & 3.7 & \\
Smokers (\%) & 25.1 & 27.3 & \\
Stages of change (among ever smokers) & & & \\
$\quad$ Precontemplation (\%) & 47.0 & 44.5 & \\
Contemplation (\%) & 14.3 & 12.5 & \\
Preparation (\%) & 4.7 & 5.3 & \\
Action (\%) & 11.7 & 13.9 & \\
Maintenance (\%) & 22.3 & 23.7 & \\
Among smokers (means) & & & \\
Cigarettes per day & 11.4 & 11.4 & 0.92 \\
Minutes to first cigarette in the morning & 68.3 & 67.7 & 0.31 \\
Pros of smoking (0-100 scale) & 44.7 & 46.0 & 0.78 \\
Cons of smoking (0-100 scale) & 61.1 & 60.7 & 0.34 \\
Smoking self efficacy (0-100 scale) & 50.4 & 47.9 & \\
\hline
\end{tabular}

intervention building and the other in the main comparison building. Cigarette sales during the campaign (March to June 1996) were compared with sales from March to June 1995. Sales figures were transmitted by the company that owns and operates these machines.

We observed directly the number of smokers and non-smokers in the "Smoking" and "No-smoking" areas of the cafeteria of the main intervention building. These areas were not modified by the programme, but we hypothesised that the programme would improve compliance of smokers with the smoking regulation in the cafeteria. A total of 17 observations sessions were conducted, each lasting 15 minutes, always on a Tuesday between 1330 and 1430. Only persons who were sitting in the cafeteria were included. We compared the proportion of smokers in the "Smoking" and "No-smoking" areas before and after the regulation was implemented.

ANALYSES

Continuous variables

Within each cohort, paired $t$ tests were used to assess changes between baseline and follow up.
For each continuous variable, we computed individual differences between baseline and follow up and compared the two cohorts in analysis of covariance models, adjusting for age and sex. No adjustment was made for status of university student, as this variable was strongly correlated with age.

\section{Dichotomous variables}

Within each group, changes between baseline and follow up in proportions (for example, per cent of smokers, per cent of participants who agreed (versus disagreed) with opinion statements) were assessed with the McNemar's test for matched data. ${ }^{17}$ The two cohorts were compared for changes between baseline and follow up by testing the heterogeneity of the McNemar's matched odds ratios across groups. ${ }^{18}$ In the example of smoking status, McNemar's odds ratio equals $b / c$ where $b=$ baseline non-smokers who smoked at follow up, and $\mathrm{c}=$ baseline smokers who did not smoke at follow up. The test for heterogeneity of McNemar's odds ratios compares b/c (intervention group) to b'/c' (comparison group), using the ratio of odds ratios, bc'/b'c. ${ }^{18}$ This analysis was adjusted for age and sex in logistic regression models.

\section{Results}

BASELINE CHARACTERISTICS OF PARTICIPANTS

At baseline, the intervention group included more men, younger participants and more students than the comparison group (table 1). Other characteristics were similar in the two groups.

ACCEPTABILITY OF THE INTERVENTION

At baseline, the majority of participants $(61 \%$ of the intervention group and $64 \%$ of the comparison group, $\mathrm{p}=0.10$ ) agreed with the following statement "Smoking should be prohibited everywhere in the university, except in limited smoking areas". Only $29 \%$ of the intervention group and $26 \%$ of the comparison group agreed that "Smoking should be prohibited everywhere in university buildings".

Table 2 Impact of a university smoke free campaign. Geneva, Switzerland, 1995-96

\begin{tabular}{|c|c|c|c|c|c|c|c|}
\hline & \multicolumn{3}{|c|}{ Intervention group } & \multicolumn{3}{|c|}{ Comparison group } & \multirow{2}{*}{$\begin{array}{l}p \text { value on } \\
\text { difference in } \\
\text { changet }\end{array}$} \\
\hline & Baseline & Follow up & $\begin{array}{l}\text { p value on } \\
\text { change }\end{array}$ & Baseline & Follow up & $\begin{array}{l}\text { p value on } \\
\text { change }\end{array}$ & \\
\hline Exposed to ETS in university (0-100 score) & 53.3 & 49.3 & $<0.001$ & 51.2 & 45.1 & $<0.001$ & 0.13 \\
\hline Bothered by ETS in university (0-100 score) & 42.0 & 34.3 & $<0.001$ & 40.4 & 32.8 & $<0.001$ & 0.30 \\
\hline \multicolumn{8}{|l|}{$\begin{array}{l}\text { Ever smokers participating in a smoking cessation programme in } \\
\text { past } 6 \text { months } \% \text { ) }\end{array}$} \\
\hline Smokers $(\%)$ & 24.8 & 25.1 & 1.0 & 27.2 & 26.7 & 0.80 & 0.47 \\
\hline \multicolumn{8}{|l|}{ Among smokers } \\
\hline Cigarettes per day (CPD) & 11.4 & 11.7 & 0.06 & 11.4 & 12.0 & 0.002 & 0.53 \\
\hline CPD smoked in university buildings & 5.5 & 5.7 & 0.14 & 5.5 & 5.0 & 0.11 & 0.035 \\
\hline CPD smoked outside the university & 6.0 & 6.5 & 0.01 & 6.8 & 7.3 & 0.13 & 0.70 \\
\hline Minutes to first cigarette in the morning & 68.0 & 67.5 & 0.85 & 67.3 & 65.6 & 0.07 & 0.23 \\
\hline Fagerström test & 1.8 & 1.8 & 0.49 & 1.8 & 1.9 & 0.10 & 0.53 \\
\hline Attempted to quit in past 4 months (\%) & 2.0 & 3.8 & 0.03 & 3.5 & 3.5 & 1.0 & 0.048 \\
\hline Precontemplation stage of change (\%) & 71.2 & 74.0 & 1.0 & 71.4 & 72.6 & 0.65 & 0.61 \\
\hline Pros of smoking ( $0-100$ score $)$ & 44.7 & 45.2 & 0.82 & 46.0 & 45.3 & 0.58 & 0.62 \\
\hline Cons of smoking (0-100 score) & 61.1 & 61.2 & 0.30 & 60.7 & 61.8 & 0.05 & 0.49 \\
\hline Self efficacy $(0-100$ score $)$ & 50.4 & 49.8 & 0.31 & 47.9 & 49.2 & 0.96 & 0.52 \\
\hline Smokers who admit to smoke where smoking is not allowed (\%) & 11.3 & 20.5 & 0.01 & 10.8 & 9.7 & 0.85 & 0.03 \\
\hline \multicolumn{8}{|l|}{ Opinions (\% agree) "In the university..." } \\
\hline $\begin{array}{l}\text { "Mutual acceptance between smokers and non-smokers is better } \\
\text { now than } 1 \text { year ago" }\end{array}$ & 3.5 & 11.9 & $<0.001$ & 3.7 & 4.2 & 0.63 & 0.001 \\
\hline "Smoking is a source of conflict" & 30.7 & 25.6 & 0.009 & 28.0 & 25.2 & 0.76 & 0.011 \\
\hline
\end{tabular}

${ }^{\star}$ Continuous variables: paired $t$ test. Dichotomous variables: McNemar test. $†$ Test on difference in change between groups, adjusted for age and sex. 


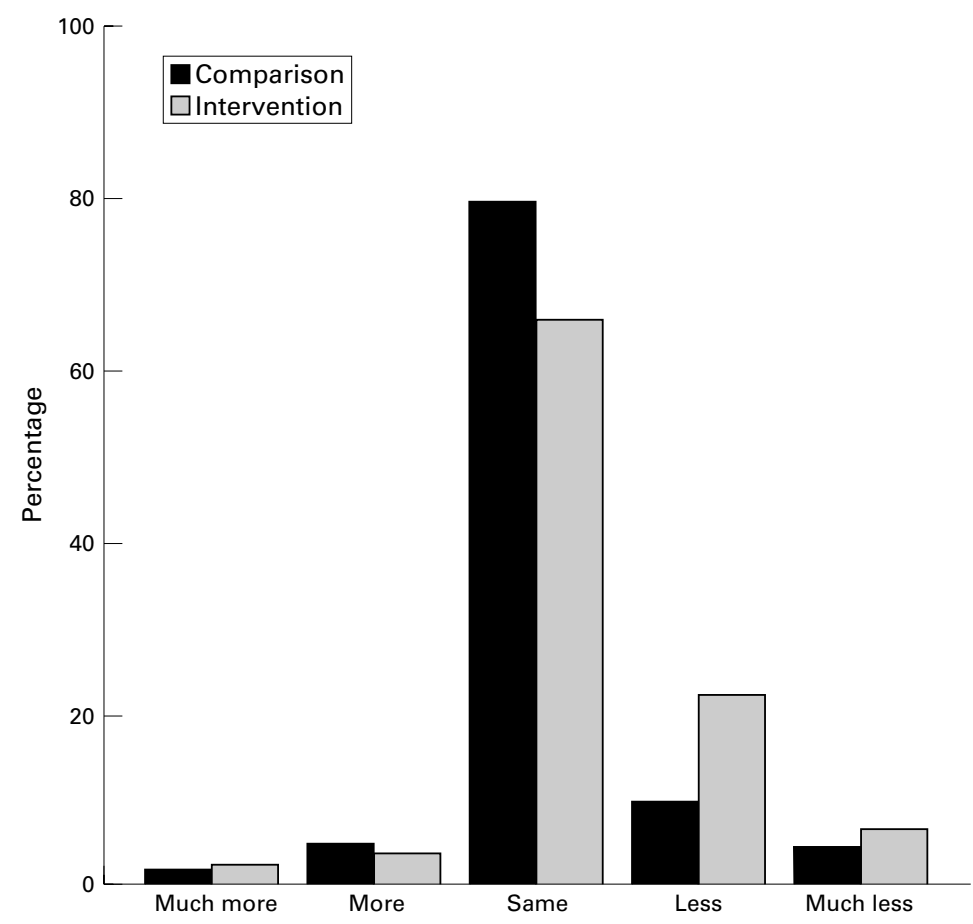

Figure 1 Retrospective assessment of bother by environmental tobacco smoke, four months after implementation of a smoke free campaign at the University of Geneva, Switzerland. Participants were asked "Compared with last year, are you now more or less bothered by ETS?"
IMPACT ON SMOKING

The proportion of smokers remained unchanged in both groups (table 2). Among participants who were smokers both at baseline and at follow up, the number of cigarettes smoked within university buildings increased slightly in the intervention group and decreased slightly in the comparison group (the difference between the two groups was small and marginally statistically significant). The proportion of smokers who made one attempt to stop smoking in the past four months almost doubled in the intervention group and remained unchanged in the comparison group (table 2). Very few participants reported participation in smoking cessation programmes, without change between baseline and follow up. The number of smokers who admitted to smoke where smoking was not permitted, in university buildings, almost doubled in the intervention cohort, but remained unchanged in the comparison cohort. In all other regards, changes over time were similar in smokers of both groups.

SMOKING CESSATION COUNSELLING SERVICE

Only eight persons contacted this service during the campaign. None of these persons entered a formal smoking cessation programme.

OPINIONS AND KNOWLEDGE ABOUT THE PROGRAMME

Opinions and knowledge about the programme were assessed only in the 833 participants who worked or studied in intervention buildings. Participants reported more positive $(n=269)$ than negative $(n=68)$ open-ended comments on the programme. Positive comments included the usefulness of such a programme (for example, "At last something is being done"). Negative comments included inadequacy of the new regulation (for example, "It was imposed rather than discussed") and poor implementation of the programme. Only half the participants knew that the programme included a general prohibition to smoke except in smoking areas (table 3). Less than half the participants said that the location of smoking areas was adequate, and only half of them said that smoking areas were respected. Several participants suggested practical solutions to improve the use and location of smoking areas.

Table 3 Opinions about and awareness of the university smoke free programme, in the intervention group, Geneva, Switzerland, 1995-96

\begin{tabular}{|c|c|c|c|c|}
\hline & $\begin{array}{l}\text { All participants } \\
(n=833)(\%)\end{array}$ & $\begin{array}{l}\text { Smokers } \\
(n=215)(\%)\end{array}$ & $\begin{array}{l}\text { Non-smokers } \\
(n=618)(\%)\end{array}$ & $p$ value \\
\hline $\begin{array}{l}\text { Did not know that a smoking prevention programme took } \\
\text { place in the university }\end{array}$ & 9 & 7 & 10 & 0.14 \\
\hline $\begin{array}{l}\text { Knew that smoking was prohibited everywhere except in } \\
\text { designated smoking areas }\end{array}$ & 52 & 54 & 51 & 0.91 \\
\hline Said that: & & & & \\
\hline location of smoking areas was adequate & 40 & 52 & 36 & $<0.001$ \\
\hline there were too many smoking areas & 13 & 4 & 17 & $<0.001$ \\
\hline there were too few smoking areas & 7 & 12 & 6 & $<0.001$ \\
\hline smoking areas were respected by smokers & 52 & 65 & 47 & $<0.001$ \\
\hline Liked the logo and the slogan & 64 & 53 & 69 & $<0.001$ \\
\hline $\begin{array}{l}\text { Thought that using lighters to disseminate the } \\
\text { programme's slogan was a good idea }\end{array}$ & 53 & 54 & 52 & 0 \\
\hline Were informed about the programme via the lighters & 30 & 40 & 26 & $<0.001$ \\
\hline
\end{tabular}


Although most participants liked the logo and slogan of the programme, several persons suggested that the readability of this logo could be improved. More participants said that using lighters to disseminate the programme's slogan was a good $(53 \%)$ than a bad idea $(24 \%)$, and $40 \%$ of smokers said that they had been informed about the programme by the lighters. However, participants wrote twice as many negative $(n=152)$ as positive $(n=83)$ comments on the idea of using lighters to disseminate the programme's slogan. Many participants did not understand this idea or thought it would be inefficient or counterproductive. Bookmarks with the programme's slogan were not appreciated, only half the stock was distributed.

CIGARETTE SALES

Cigarette sales remained stable in both the intervention $(-1.3 \%$, from 7567 to 7468 packs over four months) and the comparison buildings $(-2.6 \%$, from 1643 to 1600 packs; difference: $p=0.73)$.

DIRECT OBSERVATIONS

The proportion of smokers in the "Smoking" area of the cafeteria of the main intervention building increased from $40 \%$ to $48 \%$ after implementation of the new regulation, and the proportion of smokers in the "No-smoking" area of this cafeteria decreased from $16 \%$ to $3 \%(\mathrm{p}=0.02)$

\section{Discussion}

PROGRAMME OUTCOMES

This study examined the impact of a smoke free campaign, four months after its implementation at the University of Geneva. The most positive outcomes of this programme were an improvement in the relationships between smokers and non-smokers and an increase in the proportion of smokers who attempted to quit smoking. The latter result is encouraging, as having made previous attempts to quit predicts success of future attempts. ${ }^{19}{ }^{20}$ In a retrospective assessment, participants in the programme reported being less bothered by ETS after than before the campaign, but no between group difference was detected in prospective assessments.

The "No-smoking" area in the cafeteria of the main intervention building was better respected by smokers after the implementation of the new regulation. This result may be explained in part by the involvement of the cafeteria staff, who told us that the existence of the programme motivated them to be more active in asking smokers to respect the "No-smoking" area.

The programme had no impact on smoking prevalence, but this was not among its objectives. In countries other than Switzerland, some workplace or school smoking prevention and health promotion programmes reduced smoking prevalence, ${ }^{4521}$ but other reports are less encouraging. ${ }^{22}{ }^{23}$ Programmes that achieve change in smoking behaviour must be intensive, multifaceted, include employee participation and use social marketing techniques. ${ }^{4524}$
KEY POINTS

- A regulation prohibiting smoking everywhere but in limited areas of university buildings was acceptable and reduced the perception of bother by environmental tobacco smoke.

- This regulation did not influence smoking habits or attitudes toward smoking.

- Social marketing techniques and pre-tests should be used to improve the acceptability and impact of smoking regulations and information messages.

Most of these conditions were not met by the programme evaluated in this study.

\section{CRITIQUE OF THE PROGRAMME}

Most publications on smoking regulations in schools or workplaces studied the impact of total smoking bans..$^{6-8}$ This study brings new insight by showing that in a European educated population, in a country where smoking prevalence is high and where smoking regulations are not frequent, a regulation prohibiting smoking everywhere but in some smoking areas was a feasible and moderately effective policy. A total smoking ban would not have been acceptable in this population, as indicated by baseline data and by the high proportion of precontemplators in this group. Even though the new regulation was globally appreciated, a number of difficulties arose. Firstly, short-term compliance with the smoking restrictions was not very satisfactory. Secondly, many university members were not aware of the new regulation, the messages were not well understood and the location of smoking areas was criticised. Thirdly, very few persons used the smoking cessation counselling service. These problems could possibly have been avoided. For instance, communication materials could have been pretested in the target population and more sophisticated social marketing strategies could have been used. ${ }^{24}$ In addition, the programme might have been more effective had it been implemented directly by the university rather than by an external organisation.

ISSUES OF EVALUATION

An innovative aspect of this study was the use of psychometric scales to evaluate the programme (stages of change, "pros and cons" of smoking, nicotine dependence, self efficacy)..$^{91-13}$ No impact was measured on these scales, probably because the programme was not explicitely targeted at changing these variables. In particular, the communication materials produced by the programme covered only the new regulation, and not the health impact of smoking or quitting strategies. Ideally, smoking prevention programmes should be theory driven and target variables that predict smoking cessation, such as attitudes toward smoking, smoking related self efficacy, intention to quit smoking, and social influences. ${ }^{25}$ For instance, the stages of change model is now frequently used in worksite or community based programmes. ${ }^{22}{ }^{26}$ In schools, interventions using social influence models 
seem to be effective. ${ }^{25}$ Use of such models may have improved the impact of the Geneva programme, but even sophisticated programmes based on relevant theoretical models may have little or no impact on smoking prevalence. ${ }^{22}{ }^{23} \mathrm{~A}$ useful "side effect" of this project was the development of French language versions of widely cited questionnaires. ${ }^{11-13}$

The main limitation of this study is the short interval between programme implementation and follow up assessment. Four months may not have been enough to detect the full effects of that programme, but a longer follow up was not possible, as many students leave the university in July each year. Secondly, the study relied mostly on self completed questionnaires to assess the impact of the intervention. Self reports may be inaccurate because of imprecision of recall, socially desirable answers or misunderstanding of the questions, resulting in misclassification of respondents. ${ }^{27}$ In particular, smoking status was not biochemically validated, but biochemical validation may not be necessary nor feasible in programme evaluation. ${ }^{16}{ }^{28}$ Thirdly, seasonal effects may explain the improvements in exposure to ETS observed in both groups. The baseline survey was conducted in December, when the weather is cold in Geneva and most smokers stay inside the buildings. The follow up survey was conducted in June, when summer weather enables smokers to stay outside university buildings. These results emphasise the necessity of including a comparison group in evaluation studies. Without such a group, we would have overestimated the impact of this programme. The decrease in exposure to ETS between December and June was of similar size in both groups, thus we do not think that this seasonal effect obscured an impact of the programme.

Another limitation of this study is the incomplete follow up of intended participants. Of 2855 eligible participants, only 1856 (65\%) provided complete data at baseline and follow up. It is however not certain that incomplete participation biased the results. A study conducted in a similar population showed that the prevalence of smoking can be correctly estimated even with relatively low participation rates. ${ }^{29}$

\section{RECOMMENDATIONS}

Active participation of target audiences in programme development and implementation should be more systematically encouraged. Social marketing techniques and pre-tests should be used to improve the acceptability and impact of regulations and information messages. A smoking cessation service was not very useful in this programme, thus future programmes may devote resources to more effective activities. Finally, evaluation studies should be part of all prevention activities.

Funding: this work was supported by the University of Geneva, the Geneva Health Authority, the Swiss Foundation for Health
Promotion, the Swiss Cancer League, the Geneva Cancer League, the Geneva League Against Tuberculosis and Pulmonary Diseases, the Radix Foundation and by grants from the Swiss National Science Foundation to Drs Etter (32-4712296) and Perneger (3233-32069-91).

Conflicts of interest: none.

1 World Heath Organization. Tobacco Alert. Special issue World No Tobacco Day 1996. Geneva: WHO, 1996.

2 Le Gauffey Y, Efionayi-Mäder D, François Y, et al. Les consommations d'alcool, de tabac et de drogues des écoliers de 11 à 16 ans en Suisse. Lausanne: ISPA, 1995.

3 Ammann P, Beer V, Bisig B, et al. La santé dans le canton de Genève. Lausanne: Institut suisse de la santé publique, 1996.

4 Pelletier KR. A review and analysis of the health and cost-effective outcome studies of comprehensive health promotion and disease prevention programs at the worksite: 1991-1993 update. American fournal of Health Promotion 1993;8:50-62.

5 Fisher KJ, Glasgow RE, Terborg JR. Work site smoking cessation: a meta-analysis of long term quit rates from controlled studies. F Occup Med 1990;32:429-39.

6 Borland R, Chapman S, Owen N, et al. Effects of workplace smoking bans on cigarette consumption. Am $\mathcal{F}$ Public Health 1990;80:178-80.

7 Stave GM, Jackson GW. Effect of a total work-site smoking ban on employee smoking and attitudes. F Occup Med 1991;33:884-90.

8 Daughton, DM, Andrews CE, Orona CP, et al. Total indoor smoking ban and smoker behavior. Prev Med 1992;21:670-

9 Etter JF, Perneger TV, Ronchi A. Distributions of smokers by stage: international comparison and association with smoking prevalence. Prev Med 1997;26:580-5.

10 Etter JF, Perneger TV, Ronchi A. Collecting saliva by mail. Am f Epidemiol 1998; 147:141-6.

11 Heatherton TF, Kozlowski LT, Frecker RC, et al. The Fagerström Test for Nicotine Dependence: a revision of the Fagerström Tolerance Questionnaire. Br f Addict 1991;86: Fagerström

12 Prochaska JO, DiClemente CC, Norcross JC. In search of how people change. Applications to addictive behaviors. Am Psychol 1992;47:1102-14

13 Velicer WF, Di Clemente CC, Prochaska JO, et al. Decisional balance measure for assessing and predicting smoking status. F Pers Social Psychol 1985;48:1279-89.

14 Bandura A. Self-efficacy mechanism in human agency. $A m$ Psychol 1982;37:122-47.

15 De Vries H, Dijkstra M, Kuhlman P. Self-efficacy: the third factor beside attitude and subjective norm as a predictor of behavioural intentions. Health Education Research 1988;3: $273-82$.

16 Velicer WF, Prochaska JO, Rossi JS, et al. Assessing outcome in smoking cessation studies. Psychol Bull 1992;111:23-41.

17 Fleiss JL. Statistical methods for rates and proportions. 2nd ed. New York: John Wiley, 1981.

18 Breslow NE, Day NE. Statistical methods in cancer research. Volume I: the analysis of case-control studies. Lyon, France: International Agency for Research on Cancer, 1980.

19 Hennrikus D, Jeffery RW, Lando HA. The smoking cessation process: longitudinal observations in a working population. Prev Med 1995;24:235-44.

20 Hill HA, Schoenbach VJ, Kleinbaum DG, et al. A longitudinal analysis of predictors of quitting smoking among participants in a self-help intervention trial. Addict Behav 1994;19:159-73.

21 Jeffery RW, Kelder SH, Forster JL, et al. Restrictive smoking policies in the workplace: effects on smoking prevalence and cigarette consumption. Prev Med 1994;23:78-82.

22 Glasgow RE, Terborg JR, Hollis JF, et al. Take Heart: results from the initial phase of a worksite wellness program. Am $\mathcal{F}$ Public Health 1995;85:209-16.

23 Sorensen G, Thompson B, Glantz K, et al. Worksite-based cancer prevention: primary results from the Working Well Trial. Am 7 Public Health 1996;86:939-47.

24 Black DR, Loftus EA, Chatterjee R, et al. Smoking cessation interventions for University students: recruitment and program design considerations based
theory. Prev Med 1993;22:388-99

25 Bruvold WH. A meta-analysis of adolescent smoking prevention programs. Am $\mathcal{F}$ Public Health 1993;83:872-80.

26 Schorling JB, Roach J, Siegel M, et al. A trial of church-based smoking cessation interventions for rural African Americans. Prev Med 1997;26:92-101.

27 Lee PN. Misclassification of smoking habits and passive smoking. New York: Springer Velag, 1988.

28 The Health Benefits of Smoking Cessation: A Report of the Surgeon General. Atlanta, GA: Centers for Disease Control; 1990: DHHS publication (CDC) 90-8416.

29 Etter JF, Perneger TV. Analysis of non-response bias in a mailed health survey. F Clin Epidemiol 1997;50:1123-8. 